\title{
MicroRNA-153 suppresses cell invasion by targeting SNAI1 and predicts patient prognosis in glioma
}

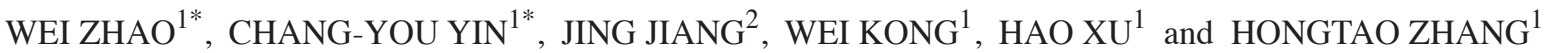 \\ ${ }^{1}$ Department of Neurosurgery, Yantai Yuhuangding Hospital; ${ }^{2}$ Department of Emergency, \\ Yantaishan Hospital, Yantai, Shandong 264000, P.R. China
}

Received January 4, 2018; Accepted November 9, 2018

DOI: $10.3892 / \mathrm{ol} .2018 .9706$

\begin{abstract}
Glioma is the most common and rapidly progressive type of malignant primary brain tumor in adults. miR-153 plays a major role in many malignancies; nevertheless, few studies have been conducted on glioma. The aim of the present study was to explore the role of miR-153 and SNAI1 on invasion in glioma. Reverse transcription-quantitative PCR was employed to measure the expression levels of miR-153 and SNAI1 mRNA. Transwell assay was utilized to calculate the capacity of invasion. Luciferase report assay was applied to detect whether SNAI1 was a target of miR-153. miR-153 was downregulated in glioma tissues and cells versus paracancerous tissues and normal immortalized gliocyte HEB cells. Transwell assay was used to measure whether a low expression of miR-153 in glioma indicated inhibition of cell invasion. We verified that SNAI1 was a target of miR-153 and had a negative association with miR-153 detected by luciferase reporter assay. Additionally, miR-153 suppressed cell invasive ability by regulating SNAI1 expression, whose partial function was reversed by SNAI1. miR-153 suppressed cell invasion of glioma by directly targeting SNAI1. Thus, miR-153/SNAI1 axis may be a novel target for cervical cancer treatment.
\end{abstract}

\section{Introduction}

Glioma, a rapidly progressive malignant brain tumor, is the most common and aggressive type of primary brain neoplasms found in adults, leading to growth of the neural microenvironment, particularly in the blood vessels (1-3). Owing to its high invasiveness, patients with glioma invariably cannot undergo surgery and when they do it is easy to relapse, resulting in short survival $(2,4)$. Glioma patients have a poor outcome with

Correspondence to: Dr Hongtao Zhang, Department of Neurosurgery, Yantai Yuhuangding Hospital, 20 Yuding East Road, Zhifu, Yantai, Shandong 264000, P.R. China

E-mail: rlv455455@163.com

*Contributed equally

Key words: miR-153, SNAI1, glioma, invasion, prognosis a 5-year survival rate of $9.8 \%$, despite multimodal treatment options including surgery, radiation and chemotherapy (5).

MicroRNAs (miRNAs), small non-coding regulatory molecules, bind to the 3'-untranslated region (3'-UTR) of target mRNAs to degrade mRNA and/or inhibit protein translation at post-transcription $(6,7)$. Increasing evidence suggests that miRNAs mediate the carcinogenic process with regard to cell proliferation, invasion and apoptosis $(8,9)$. miR-153, a novel tumor-associated miRNA is downregulated in various types of cancer, including non-small cell lung cancer, gastric cancer, breast cancer, pancreatic ductal adenocarcinoma and melanoma (10-16). miR-153 suppresses gastric cell migration and invasion by inhibiting SNAI1-induced EMT (10). miR-153 decreased the ability of migration and invasion by targeting ADAM19 in non-small cell lung cancer cells (15). A low expression of miR-153 promoted breast cancer cell apoptosis via targeting HECTD3 (13). Zeng et al observed that microRNA-153 inhibited melanoma cell proliferative and invasive abilities by targeting SNAI1 and inverse correlations between miR-153 and SNAI1 (14). However, miR-153 was found to be upregulated and promoted development and progression in colorectal and prostate cancer $(15,17)$. Thus, the roles of miR-153 seem to be different, depending on cancer types. However, the precise mechanism of miR-153 in glioma has not been investigated.

SNAI1 (snail) acts as transcription repressor and is a member of the zinc finger superfamily. SNAI1 shares conserved SNAG domain with other members at N-terminal, whose function is mediating transcription repression (18). SNAI1 is a candidate marker of epithelial-mesenchymal transition (EMT), which endows normal cells with the ability to metastasize by repressing the expression of epithelial cell marker E-cadherin (19). It has been reported that esophageal squamous cell carcinoma patients with SNAI1 high expression had worse prognosis than those with low expression of SNAI1 (20). Dong et al have reported that SNAI1 was upregulated in glioma and interference of SNAI1 could inhibit glioma cell proliferation and migration (21). However, the clinical significance of Snail in glioma remains to be determined.

In the present study, we investigated miR-153 low expression in glioma cancer tissues and cells. The results showed that miR-153 suppressed glioma cell invasion through targeting SNAI1 and SNAI1 revealed the partial function of miR-153. 
In addition, miR-153 low expression was correlated with poor prognostic parameters in glioma.

\section{Materials and methods}

Patients and clinical tissue specimens. Paired cancer tissues and corresponding paracancerous tissues were obtained from 55 patients who underwent glioma in the Yantai Yuhuangding Hospital (Yantai, China) between January 2015 and July 2017 , and were stored at $-80^{\circ} \mathrm{C}$ before analysis. None of the patients had received preoperative chemo- or radiotherapy prior to surgery. Of this cohort, patients diagnosed at early stage (I/II) were 27 , while the remaining 28 patients were at an advanced stage (III/V) (Table I). Written informed consent was obtained from patients and the study was approved by the Ethical Committee of Yantai Yuhuangding Hospital.

Cell lines and culture condition. Normal immortalized gliocyte HEB cells and the glioma cell lines U-87MG ATCC and U251 were purchased from American Type Culture Collection (cat. no. HTB-14 ${ }^{\mathrm{TM}}$; ATCC, Rockville, MD, USA). All the cells were cultured in RPMI-1640 medium containing $10 \%$ fetal bovine serum (FBS) (both from Gibco; Thermo Fisher Scientific, Inc., Waltham, MA, USA) at $37^{\circ} \mathrm{C}$ with $5 \%$ $\mathrm{CO}_{2}$. U-87MG ATCC cells were of CNS origin and are likely to be a bonafide human glioblastoma cell line considering their mRNA expression profile. Thus, U-87MG ATCC cells can be used in glioma research and are distinct from U-87MG ATCC Uppsala cells established in 1968 at the University of Uppsala (22).

Transfection. Plasmids including pcDNA3.1-SNAI1, as well as miR-153 mimic and inhibitor together with their negative control were purchased from GenePharma (Shanghai, China). Cells were seeded in 6-well plates with a density of $3 \times 10^{5}$ and cultivated at $37^{\circ} \mathrm{C}$ overnight. Lipofectamine $2000^{\mathrm{TM}}$ (Invitrogen; Thermo Fisher Scientific) was to perform the transfection in U-87MG ATCC and U251 cells, as per the manufacturer's protocol.

RNA isolation and reverse transcription quantitativePCR (RT-qPCR). Total RNAs and total miRNAs were extracted from glioma tissues and cells using TRIzol reagent (Invitrogen; Thermo Fisher Scientific) and mirVana ${ }^{\mathrm{TM}}$ miRNA Isolation kit (Ambion, Austin, TX, USA). RNAs were reverse transcribed to produce first cDNA using PrimeScript ${ }^{\mathrm{TM}}$ II 1st Strand cDNA Synthesis kit or TaqMan MicroRNA reverse Transcription kit (Takara, Dalian, China). Next, TaqMan microRNA assays and the TaqMan Gene Expression assays (Applied Biosystems; Thermo Fisher Scientific, Inc.) were applied to carried out quantitative PCR on the Step-one plus real-time PCR system (Applied Biosystems; Thermo Fisher Scientific, Inc.). The relative expression of mRNAs and miRNAs was calculated with $2^{-\Delta \Delta C q}$ method with GAPDH or U6 which were normalized, respectively (23).

Transwell assay. Transwell assay was employed to perform invasive activity with Matrigel (Clontech, Mountain View, CA, USA) added in the Transwell chamber $(8.0 \mu \mathrm{m}$ pore size; Corning Incorporated, Corning, NY, USA). Before test, we
Table I. miR-153 expression and clinicopathological features in 55 paired gliomas.

\begin{tabular}{|c|c|c|c|c|}
\hline \multirow[b]{2}{*}{$\begin{array}{l}\text { Clinicopathological } \\
\text { features }\end{array}$} & \multirow[b]{2}{*}{$\begin{array}{l}\text { Cases } \\
(n=55)\end{array}$} & \multicolumn{2}{|c|}{ miR-153 expression } & \multirow[b]{2}{*}{ P-value } \\
\hline & & $\begin{array}{l}27 \text { High } \\
(\%)\end{array}$ & $\begin{array}{l}28 \text { Low } \\
(\%)\end{array}$ & \\
\hline Age (years) & & & & $0.022^{\mathrm{a}}$ \\
\hline$<50$ & 26 & $17(53.8)$ & $9(34.6)$ & \\
\hline$\geq 50$ & 29 & $10(34.5)$ & $19(65.5)$ & \\
\hline \multicolumn{5}{|l|}{ Sex } \\
\hline Male & 28 & $15(53.6)$ & $13(46.4)$ & 0.498 \\
\hline Female & 27 & $12(44.4)$ & $15(55.6)$ & \\
\hline Tumor size (mm) & & & & 0.052 \\
\hline$\leq 4.0$ & 28 & $17(68.0)$ & $11(32.0)$ & \\
\hline$>4.0$ & 27 & $10(33.3)$ & $17(66.7)$ & \\
\hline TNM stage & & & & $0.043^{\mathrm{a}}$ \\
\hline I-II & 25 & $16(64.0)$ & $9(36.0)$ & \\
\hline III-IV & 30 & $11(36.7)$ & $19(63.3)$ & \\
\hline $\begin{array}{l}\text { Lymph node } \\
\text { metastasis }\end{array}$ & & & & $0.022^{\mathrm{a}}$ \\
\hline No & 24 & $16(66.7)$ & $8(33.3)$ & \\
\hline Yes & 31 & $11(35.5)$ & $20(64.5)$ & \\
\hline SNAI1 & & & & $0.042^{\mathrm{a}}$ \\
\hline Negative & 29 & $18(62.1)$ & $11(37.9)$ & \\
\hline Positive & 26 & $9(34.6)$ & $17(65.4)$ & \\
\hline
\end{tabular}

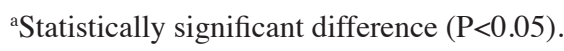

suspended glioma cells $\left(1 \times 10^{5}\right)$ using RPMI-1640 medium, and placed the Transwell chamber into 24-well plate. Cells $(200 \mu \mathrm{l})$ were then suspensded in the upper chamber, followed by the addition of $500 \mu \mathrm{l}$ medium containing $15 \%$ FBS in the lower chamber and incubation at $37^{\circ} \mathrm{C}$ for $24 \mathrm{~h}$. The cells that adhered to the lower surface were stained for about $30 \mathrm{~min}$ at $37^{\circ} \mathrm{C}$ using $0.5 \%$ crystal violet. The invasive cells were captured using a microscope (BX51 Olympus; Olympus Corporation, Tokyo, Japan) and counted at five random fields.

Protein extraction and western blot analysis. Glioma cells were lysed in RIPA lysis buffer on ice for $30 \mathrm{~min}$ and after centrifugation at at $12,000 \mathrm{x}$ g for $15 \mathrm{~min}$ at $4^{\circ} \mathrm{C}$, the supernatant was removed. Protein concentration was quantified using Bradford Protein assay kit (Bio-Rad Laboratories, Inc., Hercules, CA, USA). Equal amounts of total protein $(50 \mu \mathrm{g})$ were separated using 10\% SDS-PAGE. After electrophoresis, the blots were transferred onto PVDF membranes (Bio-Rad) and with 5\% skim milk powder. Subsequently, the membranes were incubated at $4^{\circ} \mathrm{C}$ overnight with anti-SNAI1 mouse monoclonal primary antibody (cat. no. ab167609; 1:1,000; Abcam, Cambridge, UK) and GAPDH (cat. no. G5262; 1:3,000; Sigma-Aldrich; Merck KGaA, Darmstadt, Germany) acted as internal reference. Subsequently, the membrane was incubated using mouse IgG horseradish peroxidase-conjugated secondary antibody (cat. no. sc-2357; 1:4,000; Santa Cruz Biotechnology, Inc., Santa Cruz, CA, USA) and visualized using the enhanced 
A

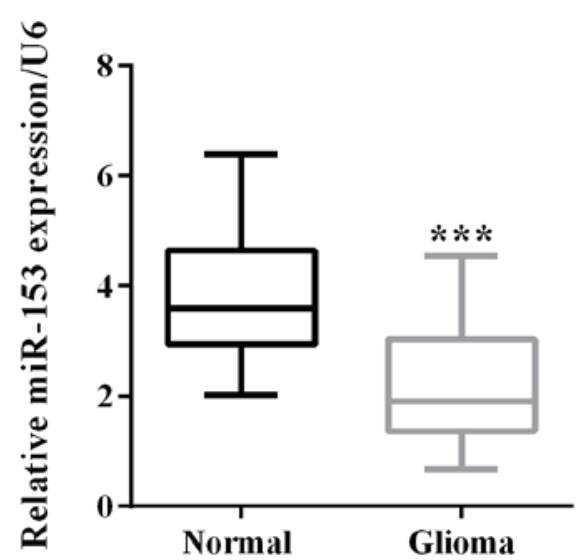

C

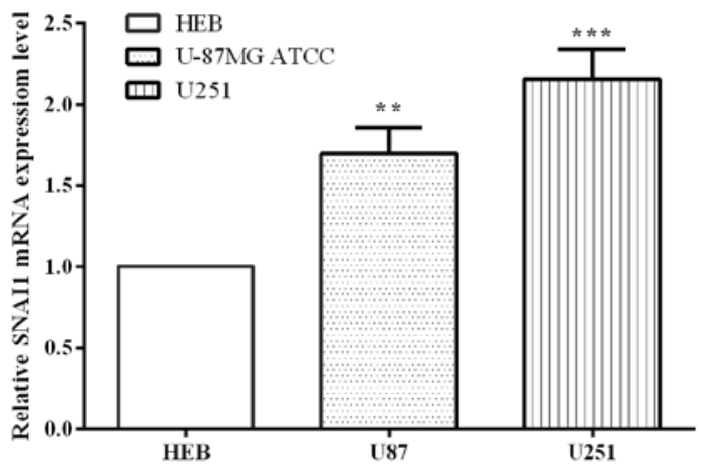

B

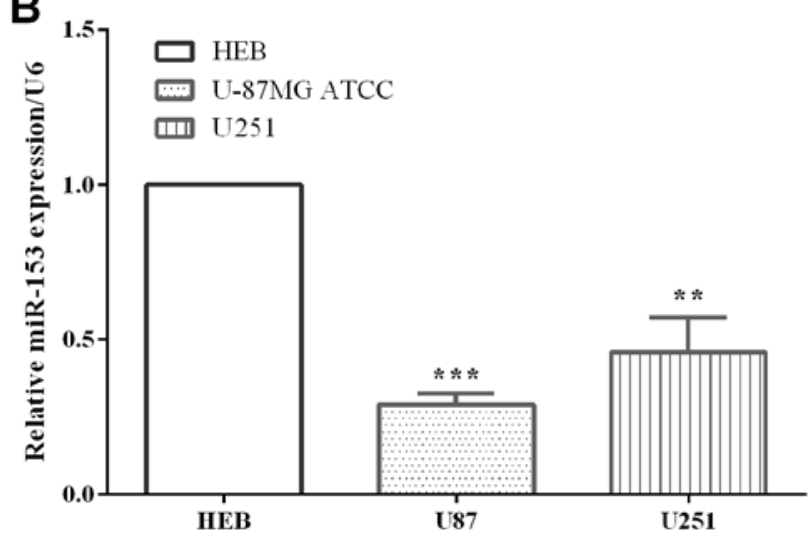

D

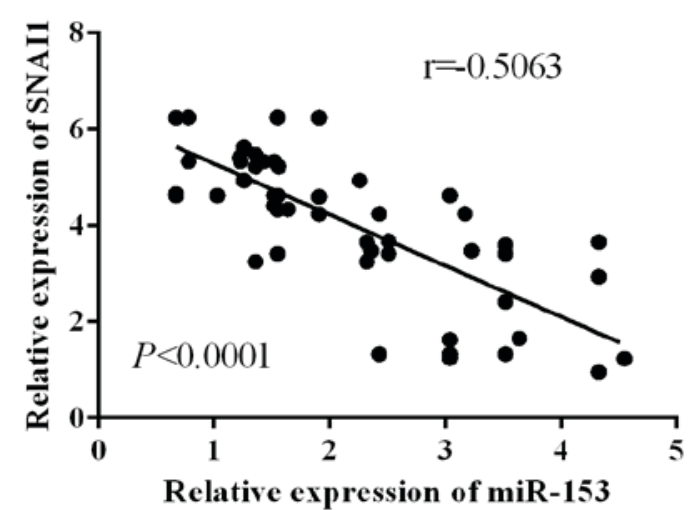

Figure 1. miR-153 expression was negatively associated with SNAI1. (A) miR-153 expression level in glioma and paracancerous tissues (normal). (B) miR-153 expression level in glioma cells U-87MG ATCC and U251 and normal immortalized gliocyte HEB cells. (C) SNAI1 mRNA level in glioma cells U-87MG ATCC and U251 and normal immortalized gliocyte HEB cells. (D) Correlation between miR-153 and SNAI1. ${ }^{* *} \mathrm{P}<0.01 ;{ }^{* * *} \mathrm{P}<0.001$.

chemiluminescence kit (ECL; EMD Millipore, Billerica, MA, USA). Densitometry was calculated using Bio-Rad Gel Doc XR instrument (Bio-Rad).

Plasmid construction and luciferase reporter assay. TargetScan (http://www.targetscan.org/vert_71/) was employed to predict target genes of miR-153 and the binding site was also predicted. The 3'UTR fragment of the target gene, containing the binding site of miR-153, was inserted into the pmirGLO Vector (WT; Promega, Madison, WI, USA). A mutant (MUT) of 3'-untranslated region (3'UTR) of the target gene was employed using QuikChange Multi Site-Directed Mutagenesis kit (Stratagene; Agilent Technologies, Inc., Santa Clara, CA, USA), according to the manufacturer's protocol. Then, miR-153 was cloned into the previously stored pmirGlo vector. We co-transfected recombinant reporter plasmids WT or MUT and either the pmirGlo-miR-153 or the miR-scramble control into U-87MG ATCC and U251 cells. After 48 h, the Dual Luciferase Reporter assay system (Promega) was utilized to measure the luciferase activities.

Statistical analysis. Student's t-test or ANOVA and Scheffe test were used to perform the statistical analysis. Pearson $\chi^{2}$ test was used to test the correlation between miR-153 and SNAI1 and clinicopathological characteristics of gastric carcinoma. Survival curves were plotted using standard
Kaplan-Meier and log-rank tests. $\mathrm{P}<0.05$ was considered to indicate a statistically significant difference.

\section{Results}

Expression of miR-153 and SNAII is inversely correlated in glioma. We assessed miR-153 level in glioma and corresponding paracancerous tissues, as well as two glioma cell lines (U-87MG ATCC and U251) and human normal immortalized gliocyte HEB cells. As expected, the relative expression of miR-153 in glioma tissues was lower than the corresponding paracancerous tissues $(\mathrm{P}<0.0001)$ (Fig. 1A). Compared with normal immortalized gliocyte HEB cells, miR-153 is downregulated in glioma cell linesU-87MG ATCC $(\mathrm{P}<0.0001)$ and $\mathrm{U} 251$ ( $\mathrm{P}=0.0010)$ (Fig. 1B). On the other hand, SNAI1 is overexpressed in glioma cell lines U-87MG ATCC $(\mathrm{P}=0.0017)$ and $\mathrm{U} 251$ ( $\mathrm{P}=0.0004)$ (Fig. 1C). Additionally, our results of miR-153 and SNAI1 expression in 55 glioma patients indicated an inverse correlation between miR-153 and SNAI1 in glioma tissue specimens $(\mathrm{P}<0.0001, \mathrm{r}=-0.7469)$ (Fig. 1D).

miR-153 low expression suppressed glioma invasion. To investigate the function of miR-153 on the invasion of glioma cells, miR-153 was upregulated/downregulated in U-87MG ATCC $(\mathrm{P}=0.0026$ and 0.0390$)$ and $\mathrm{U} 251 \quad \mathrm{P}=0.0040$ and 0.0093 ) cell line through transfected $\mathrm{miR}-153 \mathrm{mimic} / \mathrm{miR}-153$ 
A

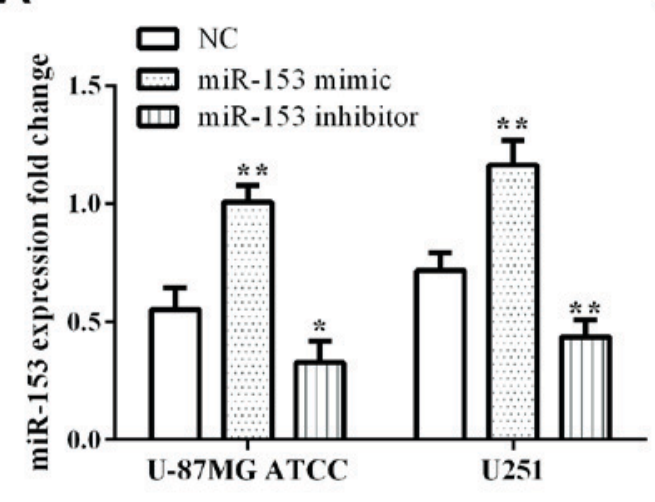

B

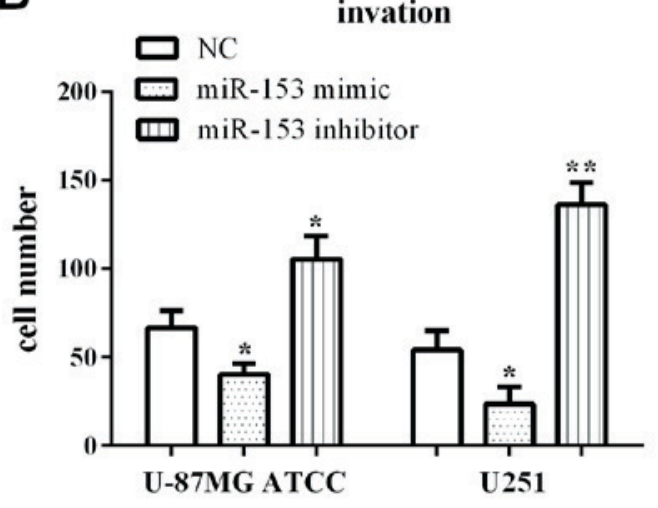

invasion

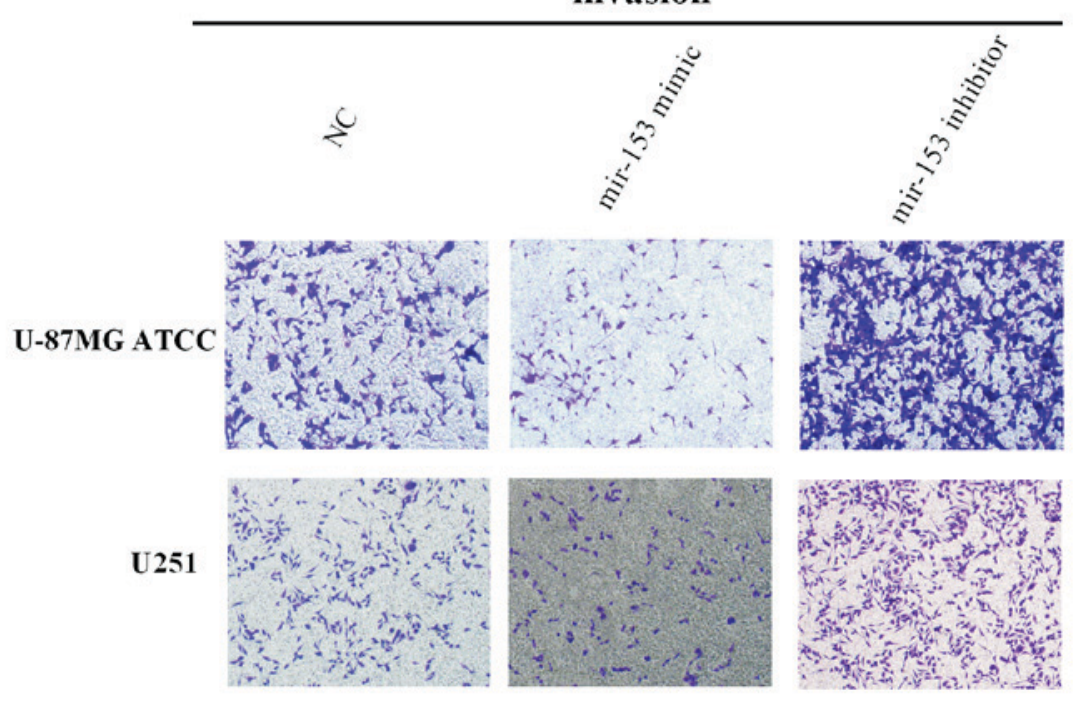

Figure 2. miR-153 inhibited glioma cell invasion. (A) RT-qPCR was applied to determine miR-153 expression following transfection of miR-153 mimic/ inhibitor in U-87MG ATCC and U251 cells. (B) The invasive capacity was measured by Transwell assay following inhibition of miR-153 in U-87MG ATCC and $\mathrm{U} 251$ cells. ${ }^{*} \mathrm{P}<0.05 ;{ }^{* *} \mathrm{P}<0.01$.

A

\begin{tabular}{|l|l|}
\hline Site:440-447 of SNAI1 \\
3'UTR WT & 5'-... ACGAGGUGUGACUAACUAUGCAA....3' \\
hsa-miR-153 & $3^{\prime}-\ldots$ CUAGUGAAAACACUGAUACGUU....5' \\
3'UTR MUT & $5^{\prime}-\ldots$ ACGAGGUGUGACUAACGAGGAAA....3'
\end{tabular}
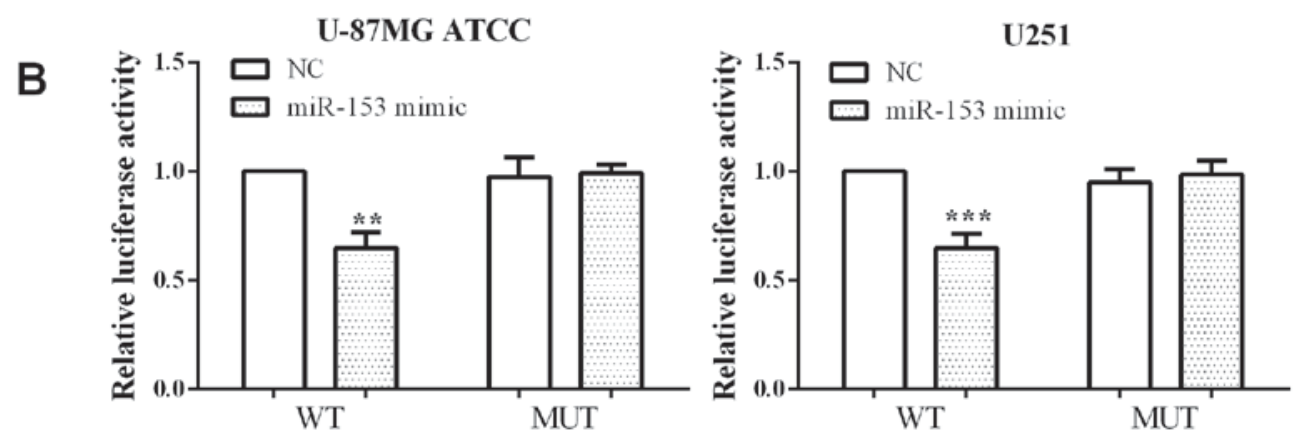

Figure 3. SNAI1 was a target of miR-153. (A) Binding site of miR-153 and the wild-type and mutant type of SNAI1 3'-UTR. (B) The relative luciferase activity when co-transfected with SNAI1 3'-UTR WT or MUT fragment and miR-153 mimic or negative control in U-87MG ATCC and U251 cells. *P $<0.01$; ${ }^{* * * *} \mathrm{P}<0.001$. WT, wild-type of SNAI1 3'UTR; MUT, mutant site of SNAI1 3'UTR. 
A
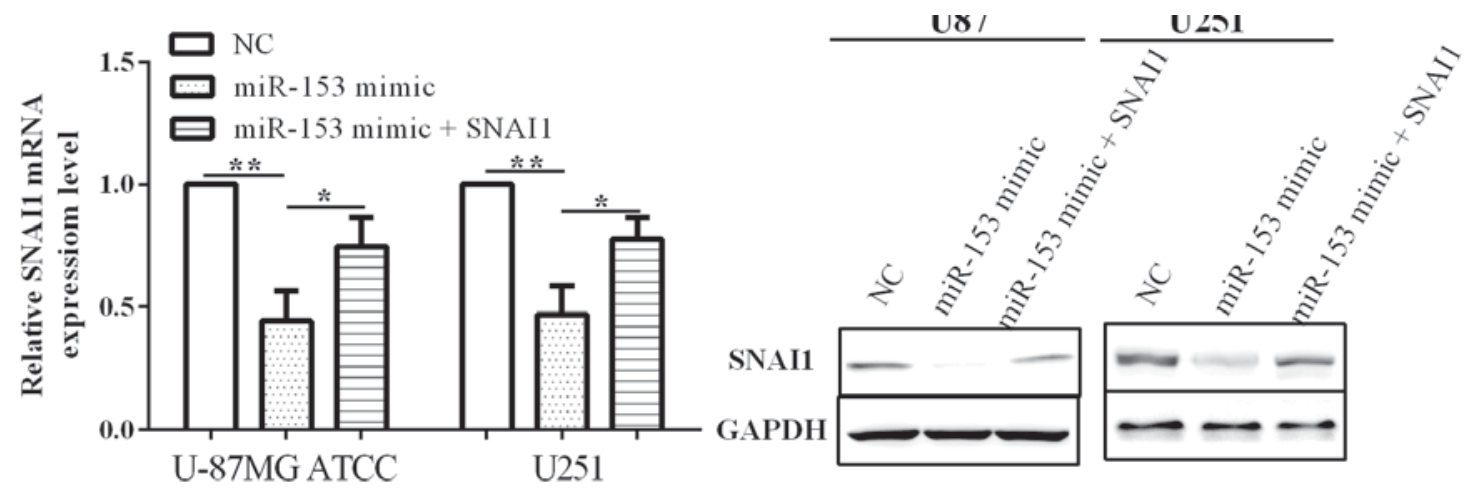

B
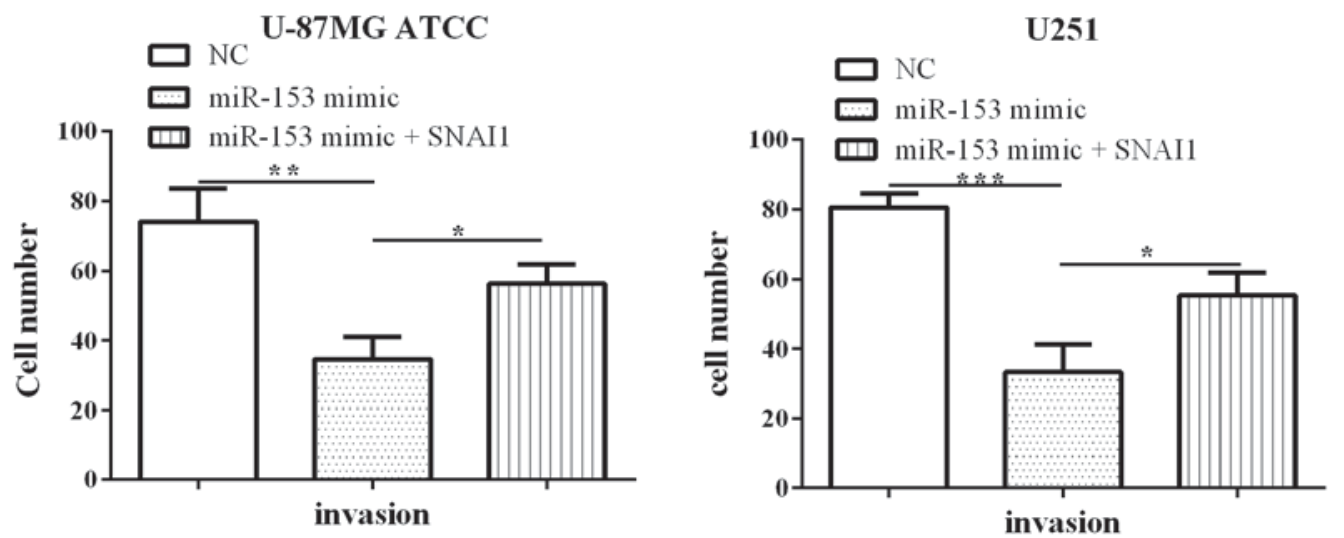

C
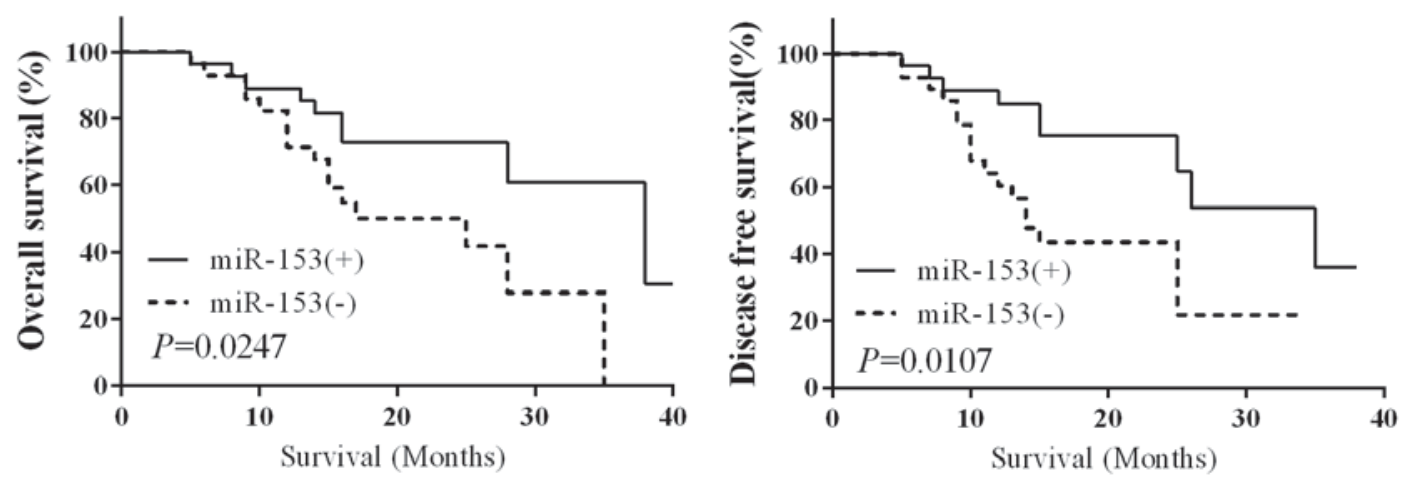

Figure 4. SNAI1 reversed the partial impact of miR-133a. (A) RT-qPCR and western blot analysis of SNAI1 expression level in U-87MG ATCC and U251 cells after transfected with miR-153 mimic and SNAI1. (B) The invasive ability of U-87MG ATCC and U251 cells following transfection with miR-153 mimic and SNAI1 compared with only transfection with miR-153. (C) Kaplan-Meier curves between miR-153 expression and glioma patients. * $<0.05$; ${ }^{* *} \mathrm{P}<0.01 ;{ }^{* * *} \mathrm{P}<0.001$. OS, overall survival; DFS, disease-free survival.

inhibitor (Fig. 2A). Transwell assays were employed to detect the influence of altering miR-153 levels on invasion. We found that the cell invasive number was significantly decreased with overexpression of miR-153 in U-87MG ATCC $(\mathrm{P}=0.0161)$ and $\mathrm{U} 251$ ( $\mathrm{P}=0.0233)$ cells. On the contrary, low expression of miR-153 significantly promoted cell invasive ability of U-87MG ATCC $(\mathrm{P}=0.0144)$ and $\mathrm{U} 251$ ( $\mathrm{P}=0.0011)$ (Fig. 2B).

miR-153 directly targeted SNAII and regulated SNAII expression. We have previously demonstrated that miR-153 affected cell invasion, however the regulation of miR-153 rmains to be determined. We identified SNAI1 was a putative binding site of miR-153 by TargetScan algorithms (http://www.targetscan. org/vert_71/). To confirm that SNAI1 is a direct target of miR-153, we mutated the binding region from CUAUGCAA to CGAGGAAA and inserted it into the pmirGlo vector (pmirGlo-SNAI1-WT or pmirGlo-SNAI1-MUT) (Fig. 3A).
We co-transfected pmirGlo-SNAI1-WT or pmirGlo-SNAI1MUT and miR-153 mimic or control into U-87MG ATCC and U251 cells. The luciferase reporter assays showed that co-transfection with miR-153 mimic and pmirGlo-SNAI1WT prominently suppressed luciferase activity compared with co-transfected control mimic and pmirGlo-SNAI1-WT in both U-87MG ATCC $(\mathrm{P}=0.0011)$ and $\mathrm{U} 251 \quad(\mathrm{P}=0.0008)$ cells. On the other hand, there was almost no difference between co-transfection with pmirGlo-SNAI1-MUT and miR-153 mimic and control in U-87MG ATCC $(\mathrm{P}=0.7854)$ and $\mathrm{U} 251(\mathrm{P}=0.5161)$ cells (Fig. $3 \mathrm{~B})$. These results suggested that miR-153 can directly target and suppress the SNAI1 expression in U-87MG ATCC and U251 cells.

SNAII reversed the partial impact of miR-153. To classify whether miR-153 suppressed invasive activity by regulating SNAI1 expression, we co-transfected miR-153 and SNAI1. 
As expected, when we transfected miR-153 mimic to overexpressed miR-153, the expression of SNAI1 was decreased both at the mRNA and protein level in U-87MG ATCC $(\mathrm{P}=0.0013)$ and $\mathrm{U} 251(\mathrm{P}=0.0016)$ cells. SNAI1 expression was reduced when transfected with miR-153 mimic $(\mathrm{P}=0.0342$ and 0.0220), which was re-expressed via transfected SNAI1 (Fig. 4A). SNAI1 overexpression partially attenuated the inhibiting effect of miR-153 on cell invasion, suggesting that SNAI1 is involved in miR-153 mediated biological function in U-87MG ATCC ( $\mathrm{P}=0.0117)$ and U251 ( $\mathrm{P}=0.0210)$ (Fig. 4B). Therefore, SNAI1 reversed the partial function of miR-153.

miR-153 low expressed predicted poor prognosis. According to miR-153 expression level, 55 gastric cancer patients were divided into the high expression group [miR-153(+)] and low expression group [miR-153(-)], with 27 and 28 patients, respectively. Detailed information on the 55 patients including factors such as sex, age, tumor size, TNM stage, lymph node metastasis and SNAI1 are presented in Table I. The results showed that the expression of miR-153 was dependent on age $(\mathrm{P}=0.022)$, TNM stage $(\mathrm{P}=0.043)$, lymph node metastasis $(\mathrm{P}=0.022)$ and SNAI1 $(\mathrm{P}=0.042)$, while had tendency association with tumor size $(\mathrm{P}=0.052)$. However, there was no correlation between miR-153 with sex $(\mathrm{P}=0.498)$.

In addition, Kaplan-Meier survival analysis of the overall survival (OS) and disease-free survival (DFS) revealed that the OS and DFS in miR-153(+) group was significantly higher than miR-153(-) group (log-rank $\mathrm{P}=0.0247$ and 0.0107) (Fig. 4C).

\section{Discussion}

Glioma is a kind of brain intrinsic tumor and limited progression concerning control thereof has been made in the past 30 years (1). High-grade glioma is among the most aggressive types of malignancy, for which there is currently no cure; therefore, finding new biomarkers for glioma is crucial (24). MicroRNAs typically block translation or degrade target messenger RNAs (mRNAs) to inhibit target gene expression at the post-transcriptional level (25-28). miR-153 was reported to be downregulated in glioma and inhibit mice tumor growth and promote ability of clone formation (24). In the present study, we determined that SNAI1 was a direct target of miR-153 in glioma cell lines U-87MG ATCC and U251. Furthermore, low expression of miR-153 in glioma tissues and cell lines was identified, while SNAI1 was lowly expressed versus corresponding paracancerous tissues and the normal immortalized gliocyte cells. In consideration of these results, we strongly believe that the impact of microRNA-153 on invasion may be through direct inhibition of SNAI1. To the best of our knowledge, this is the first time miR-153 has been suggested to directly target SNAI1 and affect invasion through regulation of SNAI1 in glioma. Additionally, this is the first study to examine the role of miR-153 on survival of patients with glioma.

The function of miR-153 on cell proliferation, migration, invasion and apoptosis has been previously studied in most cancer cells $(12,14-16,24)$. Bai et al have shown that miR-153 acts as a prognostic marker and inhibits the migratory and invasive ability of human pancreatic ductal adenocarcinoma cells by targeting SNAI1 (14). Similar findings were reported by Niu et al who identified that miR-153 inhibited cell proliferation and invasion in osteosarcoma cells by targeting TGF- $\beta 2$ (29). Similarly, our results demonstrated that miR-153 suppressed invasive capacity via targeting SNAI1 in glioma cells U-87MG ATCC and U251. Furthermore, miR-153 low expression can predict poor prognosis, and to the best of our knowledge, this is the first study to identify miR-153 is associated with the prognosis of patients with glioma.

In our study, SNAI1 was related to the impact of miR-153 on cell invasion in glioma cells U-87MG ATCC and U251. SNAI1 is a promoting factor of EMT, which endows normal cells with the ability to metastasize by repressing expression of E-cadherin (19). Furthermore, overexpressed SNAI1 has been reported in esophageal squamous cell carcinoma, pancreatic ductal adenocarcinoma and melanoma $(12,14,16)$. It has been reported that patients with high expression of SNAI1 had worse prognosis than those with low expression in esophageal squamous cell carcinoma (20). Dong et al have reported that SNAI1 was upregulated in glioma and interference of SNAI1 could inhibit glioma cell proliferation and migration (21). In our study, SNAI1 was overexpressed in glioma tissues and cell lines U-87MG ATCC and U251 versus paracancerous tissues and immortalized gliocyte HEB cells. Therefore, transfection of miR-153 mimic could inhibit SNAI1 expression, thereby causing cell invasion. In addition, SNAI1 was downregulated by miR-153 and had a negative association with the expression of miR-153 $(12,14,16)$. Consistent with all the findings, we suggest that SNAI1 is a direct target of miR-153 and is mediated by miR-153 in glioma cell invasion.

In conclusion, the present findings demonstrate that miR-153 could influence cell invasion by mediating SNAI1 expression in glioma cells. miR-153 may act as a prognostic marker to predict survival of glioma patients.

\section{Acknowledgements}

Not applicable.

\section{Funding}

No funding was received.

\section{Availability of data and materials}

The datasets used and/or analyzed during the present study are available from the corresponding author on reasonable request.

\section{Authors' contributions}

WZ and CYY contributed to the conception of the study. JJ contributed significantly to the data analysis and study preparation. WK and $\mathrm{HX}$ performed the data analyses and wrote the study. HZ helped perform the analysis with constructive discussions. All authors have read and approved the final study.

\section{Ethics approval and consent to participate}

Written informed consent was obtained from patients and the study was approved by the Ethical Committee of Yantai Yuhuangding Hospital (Yantai, China). 


\section{Patient consent for publication}

Not applicable.

\section{Competing interests}

The authors declare that they have no competing interests.

\section{References}

1. Westphal $\mathrm{M}$ and Lamszus $\mathrm{K}$ : The neurobiology of gliomas: From cell biology to the development of therapeutic approaches. Nat Rev Neurosci 12: 495-508, 2011.

2. Kwiatkowski SC, Guerrero PA, Hirota S, Chen Z, Morales JE, Aghi $M$ and McCarty JH: Neuropilin-1 modulates TGF $\beta$ signaling to drive glioblastoma growth and recurrence after antiangiogenic therapy. PLoS One 12: e0185065, 2017.

3. Louis DN: Molecular pathology of malignant gliomas. Annu Rev Pathol 1: 97-117, 2006.

4. Sayegh ET, Kaur G, Bloch O and Parsa AT: Systematic review of protein biomarkers of invasive behavior in glioblastoma. Mol Neurobiol 49: 1212-1244, 2014.

5. Munthe S, Halle B, Boldt HB, Christiansen H, Schmidt S, Kaimal V, Xu J, Zabludoff S, Mollenhauer J, Poulsen FR, et al: Shift of microRNA profile upon glioma cell migration using patient-derived spheroids and serum-free conditions. J Neurooncol 132: 45-54, 2017.

6. Siomi H and Siomi MC: Posttranscriptional regulation of microRNA biogenesis in animals. Mol Cell 38: 323-332, 2010

7. Ha M and Kim VN: Regulation of microRNA biogenesis. Nat Rev Mol Cell Biol 15: 509-524, 2014.

8. Fabbri M: MicroRNAs and cancer: Towards a personalized medicine. Curr Mol Med 13: 751-756, 2013.

9. Gonzalez-Duarte RJ, Cazares-Ordonez V and Avila-Chavez E: The microRNA biogenesis machinery: Regulation by steroid hormones and alterations in cancer. Rev Invest Clin 66: 460-464, 2014

10. Zhang Z, Sun J, Bai Z, Li H, He S, Chen R and Che X MicroRNA-153 acts as a prognostic marker in gastric cancer and its role in cell migration and invasion. Onco Targets Ther 8 357-364, 2015

11. Wang W, Peng B, Wang D, Ma X, Jiang D, Zhao J and Yu L: Human tumor microRNA signatures derived from largescale oligonucleotide microarray datasets. Int J Cancer 129: 1624-1634, 2011

12. Zuo J, Wang D, Shen H, Liu F, Han J and Zhang $X$ MicroRNA-153 inhibits tumor progression in esophageal squamous cell carcinoma by targeting SNAI1. Tumour Biol 37: 16135-16140, 2016.

13. Wu X, Li L, Li Y and Liu Z: miR-153 promotes breast cancer cell apoptosis by targeting HECTD3. Am J Cancer Res 6 : $1563-1571,2016$

14. Bai Z, Sun J, Wang $X$, Wang $H$, Pei $H$ and Zhang $Z$ : MicroRNA-153 is a prognostic marker and inhibits cell migration and invasion by targeting SNAI1 in human pancreatic ductal adenocarcinoma. Oncol Rep 34: 595-602, 2015.
15. Shan N, Shen L, Wang J, He D and Duan C: miR-153 inhibits migration and invasion of human non-small-cell lung cancer by targeting ADAM19. Biochem Biophys Res Commun 456: 385-391, 2015.

16. Zeng HF, Yan S and Wu SF: MicroRNA-153-3p suppress cell proliferation and invasion by targeting SNAI1 in melanoma. Biochem Biophys Res Commun 487: 140-145, 2017.

17. Zhang L, Pickard K, Jenei V, Bullock MD, Bruce A, Mitter R, Kelly G, Paraskeva C, Strefford J, Primrose J, et al: miR-153 supports colorectal cancer progression via pleiotropic effects that enhance invasion and chemotherapeutic resistance. Cancer Res 73: 6435-6447, 2013.

18. Nieto MA: The snail superfamily of zinc-finger transcription factors. Nat Rev Mol Cell Biol 3: 155-166, 2002.

19. Peinado H, Ballestar E, Esteller M and Cano A: Snail mediates E-cadherin repression by the recruitment of the Sin3A/histone deacetylase 1 (HDAC1)/HDAC2 complex. Mol Cell Biol 24: 306-319, 2004

20. Natsugoe S, Uchikado Y, Okumura H, Matsumoto M, Setoyama T, Tamotsu K, Kita Y, Sakamoto A, Owaki T, Ishigami S, et al: Snail plays a key role in E-cadherin-preserved esophageal squamous cell carcinoma. Oncol Rep 17: 517-523, 2007.

21. Dong Q, Cai N, Tao T, Zhang R, Yan W, Li R, Zhang J, Luo H, Shi Y, Luan W, et al: An axis involving SNAI1, microRNA-128 and SP1 modulates glioma progression. PLoS One 9: e98651, 2014.

22. Allen M, Bjerke M, Edlund $H$, Nelander S and Westermark B: Origin of the U87MG glioma cell line: Good news and bad news. Sci Transl Med 8: 54re3, 2016.

23. Livak KJ and Scmittgen TD: Analysis of relative gene expression data using real-time quantitative PCR and the 2(-Delta Delta C(T)) method. Methods 25: 402-408, 2001

24. Cui Y, Zhao J, Yi L and Jiang Y: microRNA-153 targets mTORC2 component rictor to inhibit glioma cells. PLoS One 11: e0156915, 2016.

25. Christodoulatos GS and Dalamaga M: Micro-RNAs as clinical biomarkers and therapeutic targets in breast cancer: Quo vadis? World J Clin Oncol 5: 71-81, 2014.

26. Lauressergues D, Couzigou JM, Clemente HS, Martinez Y, Dunand C, Bécard G and Combier JP: Primary transcripts of microRNAs encode regulatory peptides. Nature 520: 90-93, 2015.

27. Shukla GC, Singh J and Barik S: MicroRNAs: Processing, maturation, target recognition and regulatory functions. Mol Cell Pharmacol 3: 83-92, 2011.

28. Esquela-Kerscher A and Slack FJ: Oncomirs - microRNAs with a role in cancer. Nat Rev Cancer 6: 259-269, 2006

29. Niu G, Li B, Sun L and An C: MicroRNA-153 inhibits osteosarcoma cells proliferation and invasion by targeting TGF- $\beta 2$. PLoS One 10: e0119225, 2015.

(i) (9) This work is licensed under a Creative Commons Attribution-NonCommercial-NoDerivatives $\quad 4.0$ International (CC BY-NC-ND 4.0) License. 